\title{
The role of garlic in hepatopulmonary syndrome: A randomized controlled trial
}

\author{
Binay K De MD, Deep Dutta MD, Subrata K Pal MD, Subhabrata Gangopadhyay MBBS, \\ Sumanta Das Baksi MBBS, Adyapad Pani MBBS
}

BK De, D Dutta, SK Pal, S Gangopadhyay, S Das Baksi, A Pani. The role of garlic in hepatopulmonary syndrome: A randomized controlled trial. Can J Gastroenterol 2010;24(3):183-188.

BACKGROUND: Increased nitric oxide production in cirrhosis has been commonly implicated in the genesis of hepatopulmonary syndrome (HPS). Initial studies suggested that garlic, a constituent of the daily diet, may have a role in the treatment of HPS by altering nitric oxide production.

OBJECTIVE: To evaluate the effects of oral garlic supplementation on arterial blood gas parameters, and overall morbidity and mortality in patients with HPS.

METHODS: Twenty-one and 20 HPS patients were randomly assigned to receive either oral garlic supplementation or placebo, respectively, and were evaluated monthly over a period of nine to 18 months.

RESULTS: After nine months, garlic supplementation was associated with a $24.66 \%$ increase in baseline arterial oxygen levels $(83.05 \mathrm{mmHg}$ versus $66.62 \mathrm{mmHg} ; \mathrm{P}<0.001)$, compared with only a $7.37 \%$ increase (68.75 $\mathrm{mmHg}$ versus $64.05 \mathrm{mmHg} ; \mathrm{P}=0.02$ ) among subjects in the placebo group. There was also a $28.35 \%$ decrease in alveolar-arterial oxygen gradient $(21.35 \mathrm{mmHg}$ versus $29.77 \mathrm{mmHg}$; $<0.001)$ among patients with HPS who received garlic, in contrast with only a $10.73 \%$ decrease $(29.11 \mathrm{mmHg}$ versus $32.61 \mathrm{mmHg}$; $=0.12$ ) among those in the placebo group. After nine months, the arterial oxygen level was significantly higher $(83.05 \mathrm{mmHg}$ versus $68.75 \mathrm{mmHg}$; $\mathrm{P}<0.001)$ and the alveolar-arterial oxygen gradient was significantly lower $(21.35 \mathrm{mmHg}$ versus $29.11 \mathrm{mmHg}$; $<0.001)$ among patients receiving garlic compared with those receiving placebo. Reversal of HPS was observed in 14 of 21 patients $(66.67 \%)$ on garlic supplementation (intent-to-treat analysis) and in one of 20 patients (5\%) on placebo. Two of 21 patients undergoing garlic supplementation died during follow-up in contrast to seven of 20 patients who were on placebo. CONCLUSIONS: Garlic supplementation may be beneficial in patients with HPS for the reversal of intrapulmonary shunts as well as reducing hypoxemia and mortality.

Key Words: Duration of disease; Garlic; Hepatopulmonary syndrome; Incomplete syndrome; Mortality

$\mathrm{H}$ epatopulmonary syndrome (HPS) is defined by the presence of hepatic dysfunction or portal hypertension, a widened age-corrected alveolar-arterial oxygen gradient on room air with or without hypoxemia, and intrapulmonary vasodilation $(1,2)$. Its natural history, pathogenesis and management has yet to be fully elucidated, although intrapulmonary vascular dilation, predominantly at the base of the lungs, has been implicated (3-5). Low pulmonary vascular resistance, normal or low pulmonary arterial pressure, and high cardiac output

\section{Le rôle de l'ail dans le syndrome hépatopulmonaire : Un essai aléatoire et contrôlé}

HISTORIQUE : Une production accrue de monoxyde d'azote en cas de cirrhose est souvent impliquée dans la genèse du syndrome hépatopulmonaire (SHP). Des études initiales laissent croire que l'ail, un élément du régime quotidien, contribuerait au traitement du SHP en altérant la production de monoxyde d'azote.

OBJECTIF : Évaluer les effets des suppléments d'ail par voie orale sur les paramètres de la gazométrie artérielle et sur la morbidité et la mortalité globales des patients ayant un SHP.

MÉTHODOLOGIE : Vingt et un et 20 patients atteints du SHP répartis au hasard ont reçu respectivement des suppléments d'ail par voie orale ou un placebo ainsi qu'une évaluation mensuelle pendant une période de neuf à 18 mois.

RÉSULTATS : Au bout de neuf mois, les suppléments d'ail s'associaient à une augmentation de 24,66 \% des taux d'oxygène artériel de départ $(83,05 \mathrm{mmHg}$ par rapport $66,62 \mathrm{mmHg} ; \mathrm{P}<0,001)$, comparablement à une augmentation de seulement 7,37 \% $(68,75 \mathrm{mmHg}$ par rapport à $64,05 \mathrm{mmHg}$; $\mathrm{P}=0,02$ ) chez les sujets du groupe prenant un placebo. De plus, on constatait une diminution de $28,35 \%$ du gradient d'oxygène alvéolaireartériel $(21,35 \mathrm{mmHg}$ par rapport à $29,77 \mathrm{mmHg} ; \mathrm{P}<0,001)$ chez les patients atteints d'un SHP qui avaient pris de l'ail, par rapport à une diminution de seulement $10,73 \%(29,11 \mathrm{mmHg}$ par rapport à $32,61 \mathrm{mmHg} ; \mathrm{P}=0,12)$ chez ceux prenant un placebo. Au bout de neuf mois, le taux d'oxygène artériel était considérablement plus élevé $(83,05 \mathrm{mmHg}$ par rapport à $68,75 \mathrm{mmHg} ; \mathrm{P}<0,001)$ et le gradient d'oxygène alvéolaire-artériel était considérablement plus faible $(21,35 \mathrm{mmHg}$ par rapport à $29,11 \mathrm{mmHg}$; $\mathrm{P}<0,001$ ) chez les patients qui prenaient de l'ail par rapport à ceux qui prenaient un placebo. On a observé la suppression du SHP chez 14 des 21 patients $(66,67 \%)$ qui prenaient des suppléments d'ail (analyse en intention de traiter) et chez un des 20 patients (5\%) qui prenaient un placebo. Deux des 21 patients qui prenaient des suppléments d'ail sont décédés pendant le suivi, par rapport à sept des 20 patients qui prenaient un placebo.

CONCLUSIONS : Les suppléments d'ail peuvent être bénéfiques chez des patients atteints du SHP pour supprimer les dérivations intrapulmonaires et réduire l'hypoxémie ainsi que la mortalité.

have been observed in patients with HPS $(6,7)$. The persistent pulmonary and systemic vasodilation observed in patients with HPS has been explained as an imbalance between vasodilator and vasoconstrictor agents that favour vasodilation. Numerous vasodilators have been implicated; however, nitric oxide (NO) is the most recognized. A variety of therapeutic agents such as almitrine, somatostatin analogues, methylene blue and pentoxifylline have been used in the treatment of HPS with mixed results. Theoretically, these agents were promising

Department of Medicine, Medical College Calcutta, India

Correspondence: Dr Binay K De, 64/4A/1A Dr SC Banerjee Road, Calcutta 700010, India. Telephone 00-91-33-23731060,

fax 00-91-33-22800549, e-mail binaykde@hotmail.com

Received for publication August 8, 2008. Accepted March 9, 2009 
because of their effect of enhancing vasoconstriction (almitrine, somatostatin analogues) or inhibiting vasodilation (methylene blue) (8-11). Overall, however, initial attempts to develop pharmacotherapy for this complication of portal hypertension have not been encouraging (8-11). The only definitive treatment to date has been liver transplantation (12-16). Encouraging results have been obtained with cavoplasty (17) in selected patients with HPS secondary to Budd-Chiari syndrome. Also, coil embolotherapy has been found to be beneficial in selected HPS patients (18). The prevailing clinical interest in developing effective pharmacotherapy for HPS is based on the relatively high prevalence of subclinical and clinical disease (5\% to $29 \%$ of patients with end-stage liver disease [19]), and a high mortality rate (41\% over an approximate three-year period [20]), despite clinically stable hepatic dysfunction. Unfortunately, liver transplantation is not an option available to the majority of patients with HPS in several countries and, therefore, the need to develop effective pharmacotherapy for this condition is heightened.

Garlic (Allium sativum), a common constituent of the daily diet, has a long history of being an herb of unique taste and odour, and has some medicinal qualities. Improvement in a patient with HPS taking garlic was first reported in 1992 (21). Abrams and Fallon (22) found garlic to be an effective therapy for HPS in a small cohort of young patients. Similar encouraging results of garlic therapy were reported in children with HPS (23). However, in spite of the initial success, studies in a large cohort of subjects with HPS have been lacking. The aim of the present study was to evaluate the effects of oral garlic supplementation on arterial blood gas parameters in patients with HPS, and to observe any changes in overall morbidity and mortality in this patient population.

\section{METHODS}

A total of 353 consecutive patients with portal hypertension were examined in the Liver Clinic of the Medical College and Hospital (Calcutta, India). The present study was performed from May 2006 to June 2008. All patients underwent routine investigations (eg, complete hemogram, urea, serum creatinine, random sugar and electrolytes) and tests (eg, chest x-ray, pulmonary function tests, contrast-enhanced computed tomography of the thorax and echocardiography) to rule out intrinsic cardiopulmonary disease. Patients with intrinsic cardiopulmonary disease (eg, asthma, chronic obstructive lung disease, diffuse parenchymal lung disease, pleural effusion or intracardiac shunts), massive ascites, septicemia, uncontrolled hypertension or diabetes, or any associated severe comorbid states such as malignancy or chronic renal failure, were excluded.

A total of 275 subjects with portal hypertension without evidence of intrinsic cardiopulmonary disease were screened for the presence of HPS. The procedures were explained to the patients, who were included after informed written consent was obtained. Arterial oxygen saturation was estimated in all patients using pulse oximetry, initially supine, then again after standing for $5 \mathrm{~min}$. Orthodeoxia was defined as a fall in oxygen saturation of $5 \%$ or more (24). All measurements were made in triplicate, from which an average was calculated. All 275 patients underwent transthoracic contrast-enhanced echocardiography (CEE) (Sonos 4500, Philips, India) using a standard protocol (20). CEE was performed in the echocardiography laboratory of the
Department of Cardiology. All patients underwent arterial blood gas analysis immediately after CEE. Arterial blood gas samples were obtained with an arterial catheter that was inserted as clinically indicated. Samples were analyzed using a fully automated blood gas analyzer (OPTI CCA PD7013, Osmetech, USA). The alveolar-arterial gradient for the partial pressure of oxygen was calculated by using the alveolar gas equation. The normal age-related threshold for the alveolararterial difference for the partial pressure of oxygen was calculated using the following formula (25):

$$
\text { Normal }=10+0.43(\text { age }-20)
$$

Patients with evidence of intrapulmonary vascular dilation (IPVD) detected by positive CEE were further divided into two groups based on arterial blood gas analysis.

\section{Group A: HPS}

Patients with clinical, biochemical or radiological evidence of portal hypertension, with or without hepatic dysfunction, with evidence of IPVD detected by two-dimensional CEE (CEE positivity defined as the appearance of bubbles in the left side of the heart between the fourth and sixth cardiac cycles) and elevated alveolar-arterial difference for the partial pressure of oxygen above the age-related threshold, were assigned to group A.

\section{Group B: Incomplete syndrome}

Patients with clinical, biochemical or radiological evidence of portal hypertension, with or without hepatic dysfunction, with evidence of IPVD detected by two-dimensional CEE and a normal alveolar-arterial difference for the partial pressure of oxygen for that age, were assigned to group B.

The remaining patients without evidence of IPVD were classified as controls (group C).

Patients with HPS due to Budd-Chiari syndrome were subsequently excluded because they were previously treated with cavoplasty and stent placement. The remaining HPS patients were divided into two groups based on a computer-generated randomized table: group 1 was comprised of patients receiving garlic and group 2 consisted of patients receiving placebo.

Garlic was administered orally in the form of gelatin capsules containing garlic oil (250 mg) (Garlic Pearls, Ranbaxy, India), an over the counter medication in India, in doses ranging from $1 \mathrm{~g} / \mathrm{m}^{2} /$ day to $2 \mathrm{~g} / \mathrm{m}^{2} /$ day, based on previous studies of garlic supplementation in humans $(23,26)$. The capsules (garlic or placebo) were dispensed to the patients from the Liver Clinic on a monthly basis. The patients were advised to take the capsules in two divided doses with meals. The patients, investigators and statistician were blinded to the nature of treatment given. The patients continued to receive the capsules (garlic or placebo) for the duration of study.

During the study, patients continued to receive medication for their primary disease (antiviral medications for hepatitis Band hepatitis C-associated liver disease, prednisolone for patients with autoimmune liver disease, zinc for Wilson's disease, and primary or secondary prophylaxis for variceal bleeding with beta-blockers and spironolactone). The use of pentoxifylline and nonsteroidal anti-inflammatory drugs were not permitted. Patients were counselled about strict abstinence from alcohol and smoking. 


\section{Follow-up}

All patients were followed on a monthly basis in the Liver Clinic. During follow-up, the patients were clinically examined, queried about drug compliance and any possible drug complications, and abstinence from alcohol and smoking. Patients with a history of alcohol intake were removed from subsequent analysis. Arterial oxygen saturation estimation, arterial blood gas analysis and CEE were repeated every three months during follow-up. Blood tests and an ultrasound-guided abdominal examination with or without Doppler were also repeated every three months. Patients with evidence of reversal of intrapulmonary vascular shunts indicated by a negative CEE and normalization of alveolar arterial oxygen gradient on follow-up, were classified as responders.

\section{Statistical analysis}

Comparisons were made with Student's $t$ tests for continuous variables, Fisher's exact test for binary variables and the $\chi^{2}$ test for categorical variables. Results pertaining to continuous variables were expressed as mean \pm SD. Survival curves were estimated according to the Kaplan-Meier method and were compared using the log-rank test. Survival comparisons between groups were based on an intent-to-treat analysis, with $\mathrm{P}<0.05$ considered to be statistically significant.

\section{RESULTS}

Data were collected and analyzed for the 275 patients with portal hypertension without intrinsic cardiopulmonary disease, of whom 60 had evidence of IPVDs indicated by a positive CEE. Of these 60 patients, 48 ( $17.45 \%$ of the 275 patients) had an increased alveolar-arterial difference for the partial pressure of oxygen above the age-related threshold and were diagnosed with HPS (group A). Twelve patients ( $4.36 \%$ of the 275 patients) had evidence of IVPD, with a normal alveolararterial difference for the partial pressure of oxygen for their age and were diagnosed with incomplete syndrome (IS) (group B). The remaining 215 patients who had no evidence of IPVD were classified as group C. The study design and follow-up is elaborated in Figure 1.

Cyanosis, clubbing and spider angioma were present in 38 (79.16\%), $42(87.5 \%)$ and $11(22.72 \%)$ patients with HPS, respectively, compared with only two (16.67\%), two (16.67\%) and one $(8.33 \%)$ patient(s) with IS. Orthodeoxia was significantly higher in patients with HPS (31 of 48 patients [64.58\%]) than in those with IS (three of 12 patients [25\%]; $\mathrm{P}=0.01$ ). Orthodeoxia was present in five of six patients with HPS due to Budd-Chiari syndrome. Twenty-six of the 42 patients with HPS who were randomly assigned to receive garlic or placebo had orthodeoxia.

A conservative estimate of disease duration was made based on the date the patient became aware of his or her illness to the date they entered the study. The duration of liver disease was significantly longer among patients with HPS $(12.73 \pm 6.56$ years) and IS $(11.8 \pm 9.69$ years) than in group $C(8.66 \pm 7.32$ years; $\mathrm{P}=0.002$ ). Model for End-stage Liver Disease (MELD) score was higher in patients with HPS $(15.98 \pm 6.18)$ than in those with IS (14.45 \pm 4.3$)$, but not statistically significant $(\mathrm{P}=0.56)$. The MELD score of the patients in group $\mathrm{C}$ was only marginally lower $(13.07 \pm 5.61)$.

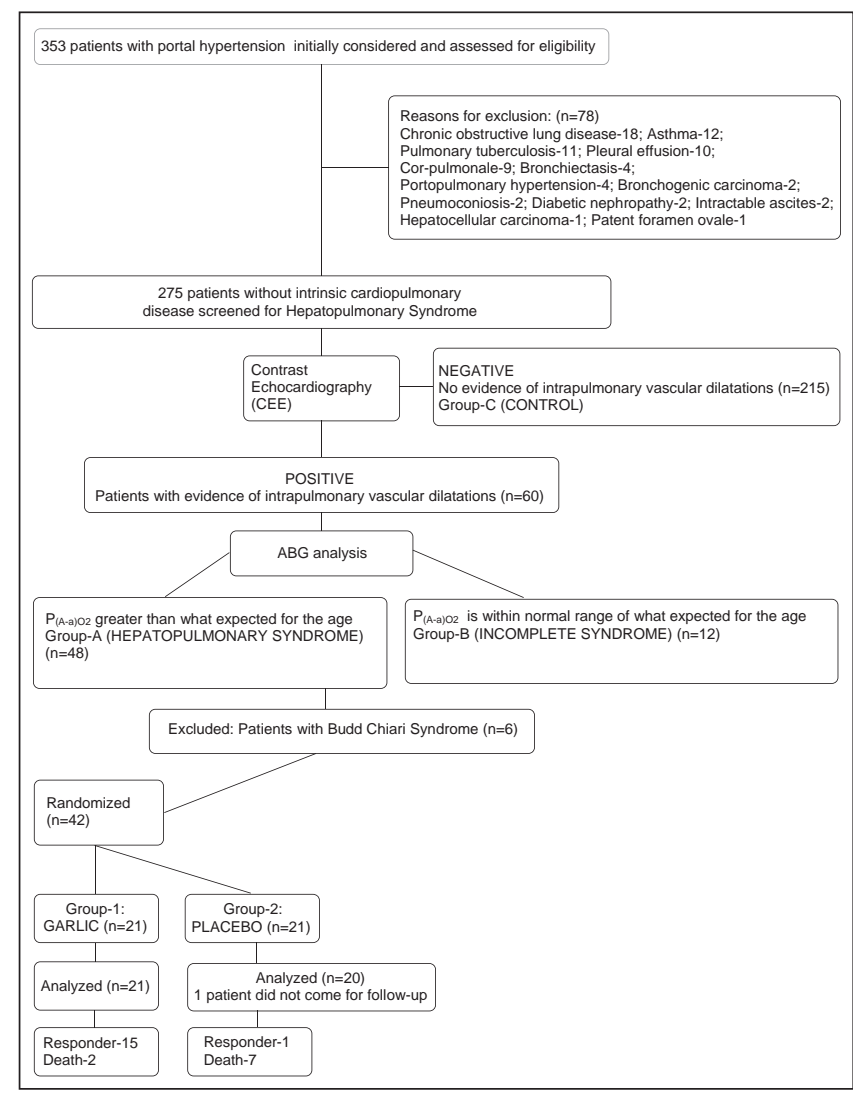

Figure 1) Summary of trial design and follow-up. ABG Arterial blood gas; $\mathrm{P}_{(\mathrm{A}-a)} \mathrm{O}_{2}$ Alveolar-arterial oxygen gradient

Of the 48 patients in group A, six patients had HPS due to Budd-Chiari syndrome and were treated with cavoplasty and stent placement and were consequently excluded. The remaining 42 patients were divided into two groups by computer-generated randomized table, 21 patients in group 1 (patients receiving garlic) and 21 patients in group 2 (patients receiving placebo). One patient in group 2 did not return for follow-up. Therefore, 41 patients (21 patients in group 1 and 20 patients in group 2) were analyzed for the effects of garlic versus placebo. There were no significant differences in the baseline clinical, biochemical or blood gas profile of patients with HPS in group 1 or group 2 (Table 1). The mean dose of garlic taken by patients in group 1 was $1.55 \pm 0.29 \mathrm{~g} /$ day.

The total duration of follow-up ranged from a minimum of nine months to a maximum of 18 months. No serious adverse effects were documented in either of the groups.

There was a $24.66 \%$ increase in baseline arterial oxygen levels (83.05 mmHg versus $66.62 \mathrm{mmHg} ; \mathrm{P}<0.001)$ after nine months of follow-up in patients with HPS who received garlic. In contrast, only a $7.37 \%$ increase $(68.75 \mathrm{mmHg}$ versus $64.05 \mathrm{mmHg}$; $\mathrm{P}=0.02$ ) was observed in individuals in the placebo group. In addition, there was a $28.35 \%$ decrease in alveolar-arterial oxygen gradient $(21.35 \mathrm{mmHg}$ versus $29.77 \mathrm{mmHg}$; $<0.001)$ after nine months of follow-up among patients with HPS receiving garlic, in contrast to a $10.73 \%$ decrease $(29.11 \mathrm{mmHg}$ versus $32.61 \mathrm{mmHg} ; \mathrm{P}=0.12$ ) among those in the placebo group. The arterial oxygen level was significantly higher in patients receiving garlic compared with those receiving placebo after nine months of follow-up $(83.05 \mathrm{mmHg}$ versus $68.75 \mathrm{mmHg}$; 
TABLE 1

Baseline clinical, biochemical and arterial blood gas profiles of patients with hepatopulmonary syndrome taking garlic (group 1) or placebo (group 2)

\begin{tabular}{|c|c|c|c|}
\hline Parameter & $\begin{array}{c}\text { Group } 1 \\
(n=21)\end{array}$ & $\begin{array}{c}\text { Group } 2 \\
(n=20)\end{array}$ & $\mathbf{P}$ \\
\hline Age, years & $37.6 \pm 13.06$ & $40.0 \pm 14.11$ & 0.40 \\
\hline Male:female, n & $17: 4$ & $18: 2$ & \\
\hline \multicolumn{4}{|l|}{ Etiology, $\mathrm{n}$} \\
\hline Alcoholic liver disease & 7 & 9 & \\
\hline Chronic hepatitis B infection & 5 & 8 & \\
\hline Chronic hepatitis $\mathrm{C}$ infection & 2 & - & \\
\hline Autoimmune & 2 & 1 & \\
\hline Wilson's disease & 1 & - & \\
\hline Cryptogenic & 4 & 2 & \\
\hline Disease duration, years & $14.23 \pm 5.04$ & $14.05 \pm 6.56$ & 0.92 \\
\hline Orthodeoxia, n & 14 & 12 & $0.91^{*}$ \\
\hline Cyanosis, n & 17 & 15 & $0.93^{*}$ \\
\hline Clubbing, $\mathrm{n}$ & 19 & 18 & $0.63^{*}$ \\
\hline Spider angioma, $\mathrm{n}$ & 3 & 5 & $0.64^{*}$ \\
\hline Alanine aminotransferase, $\mathrm{U} / \mathrm{mL}$ & $56.27 \pm 25.47$ & $63.63 \pm 41.36$ & 0.60 \\
\hline $\mathrm{SO}_{2}, \mathrm{mmHg}$ & $93.86 \pm 1.15$ & $93.7 \pm 1.08$ & 0.66 \\
\hline $\mathrm{PaO}_{2}, \mathrm{mmHg}$ & $66.62 \pm 5.59$ & $64.05 \pm 4.68$ & 0.12 \\
\hline $\mathrm{P}_{(\mathrm{A}-\mathrm{a})} \mathrm{O}_{2}, \mathrm{mmHg}$ & $29.77 \pm 6.10$ & $32.61 \pm 4.88$ & 0.11 \\
\hline MELD score & $14.58 \pm 5.28$ & $15.75 \pm 6.94$ & 0.59 \\
\hline \multicolumn{4}{|l|}{ Child-Pugh score } \\
\hline Child's class A & 3 & 4 & $0.94^{*}$ \\
\hline Child's class B & 7 & 3 & $0.32^{*}$ \\
\hline Child's class C & 11 & 13 & $0.62^{*}$ \\
\hline
\end{tabular}

Data presented as mean $\pm S D$ unless indicated otherwise. *Value calculated by $\chi^{2}$ test. MELD Model for End-Stage Liver Disease; $\mathrm{P}_{(\mathrm{A}-\mathrm{a})} \mathrm{O}_{2}$ Alveolar-arterial oxygen gradient; $\mathrm{PaO}_{2}$ Partial pressure of oxygen in arterial blood; $\mathrm{SO}_{2}$ Oxygen saturation detected by pulse oximetry

$\mathrm{P}<0.001)$. Also, the alveolar-arterial oxygen gradient was significantly lower in patients receiving garlic compared with those receiving placebo after nine months $(21.35 \mathrm{mmHg}$ versus $29.11 \mathrm{mmHg} ; \mathrm{P}<0.001)$. Table 2 summarizes the clinical and arterial blood gas profiles of patients on garlic or placebo during follow-up.

In group 1, 10 patients became HPS negative (ie, responder) three months after commencement of oral garlic therapy, two patients after six months and three patients became responders after nine months of garlic supplementation. The reversal of CEE was associated with the reversal of cyanosis, spider angioma and clubbing (Table 2). One of the responders to garlic supplementation died after three months of follow-up, following an episode of massive upper gastrointestinal bleeding. Another patient in group 1, in whom HPS did not reverse, died after 15 months of follow-up, following chronic hepatic encephalopathy and sepsis that did not respond to conservative management.

Among the patients in group 2 (placebo), one patient had reversal of HPS (responder) after six months of follow-up. In the remaining patients, in spite of the persistence of IVPD indicated by a positive CEE, there was a progressive, albeit mild improvement in arterial oxygen saturation, with a reduction in the alveolar-arterial oxygen gradient (Table 2). The incidence of complications was much higher among patients in group 2 (placebo) than among those in group 1 (garlic). Of the patients in group 2, two died within three months of follow-up, one due
TABLE 2

Evolution of clinical and arterial blood gas profile of patients with hepatopulmonary syndrome on garlic supplementation (group 1) or placebo (group 2) during follow-up $(n=41)$

\begin{tabular}{|c|c|c|c|c|c|}
\hline \multirow{2}{*}{$\begin{array}{l}\text { Parameter, } \\
\text { group }\end{array}$} & \multirow{2}{*}{$\begin{array}{c}\text { At } \\
\text { diagnosis }\end{array}$} & \multicolumn{4}{|c|}{ Follow-up, months } \\
\hline & & 3 & 6 & 9 & 12 \\
\hline \multicolumn{6}{|l|}{ Patients, $n$} \\
\hline Group 1 & 21 & 21 & 20 & $20 *$ & 7 \\
\hline Group 2 & 20 & 18 & 17 & 16 & 7 \\
\hline \multicolumn{6}{|c|}{ Responder, n } \\
\hline Group 1 & - & 10 & 11 & $14^{*}$ & 7 \\
\hline Group 2 & - & - & 1 & 1 & - \\
\hline \multicolumn{6}{|l|}{ Death, $\mathrm{n}$} \\
\hline Group 1 & - & - & 1 & - & - \\
\hline Group 2 & - & 2 & 1 & 1 & 2 \\
\hline \multicolumn{6}{|l|}{ Cyanosis, n } \\
\hline Group 1 & 17 & 7 & 3 & - & - \\
\hline Group 2 & 15 & 13 & 10 & 9 & 4 \\
\hline \multicolumn{6}{|l|}{ Clubbing, $\mathrm{n}$} \\
\hline Group 1 & 19 & 19 & 16 & 14 & 2 \\
\hline Group 2 & 18 & 16 & 15 & 14 & 7 \\
\hline \multicolumn{6}{|c|}{ Spider angioma, $\mathrm{n}$} \\
\hline Group 1 & 3 & 1 & - & - & - \\
\hline Group 2 & 5 & 3 & 2 & 2 & - \\
\hline \multicolumn{6}{|l|}{$\mathrm{SO}_{2}, \mathrm{mmHg}$} \\
\hline Group 1 & $93.86 \pm 1.15$ & $95.75 \pm 2.41$ & $96.82 \pm 2.88$ & $98 \pm 1.03$ & $98.67 \pm 0.7$ \\
\hline Group 2 & $93.70 \pm 1.08$ & $93.5 \pm 1.16$ & $93.5 \pm 2.41$ & $93.4 \pm 3.18$ & $93.7 \pm 0.95$ \\
\hline \multicolumn{6}{|c|}{$\mathrm{PaO}_{2}, \mathrm{mmHg}$} \\
\hline Group 1 & $66.62 \pm 5.59$ & $73.95 \pm 6.21$ & $82.2 \pm 5.97$ & $83.05 \pm 5.88^{\star \star}$ & $84.56 \pm 3$ \\
\hline Group 2 & $64.05 \pm 4.68$ & $65.66 \pm 7.12$ & $67.23 \pm 4.86$ & $68.75 \pm 5^{\star *}$ & $70.14 \pm 4$ \\
\hline \multicolumn{6}{|c|}{$\mathrm{P}_{(\mathrm{A}-\mathrm{a})} \mathrm{O}_{2}, \mathrm{mmHg}$} \\
\hline Group 1 & $29.77 \pm 6.10$ & $25.8 \pm 5.64$ & $21.75 \pm 5.77$ & $21.35 \pm 5.86^{\star \star *}$ & $17.2 \pm 3$ \\
\hline Group 2 & $32.61 \pm 4.88$ & $32.38 \pm 7.42$ & $29.86 \pm 5.64$ & $29.11 \pm 4.79^{\star \star \star}$ & $28.88 \pm 3.9$ \\
\hline
\end{tabular}

Data presented as mean $\pm S D$ unless indicated otherwise. *Total number of patients is 20 instead of 21 and total number of responders is 14 instead of 15, because one of the responders died after three months of follow up. ${ }^{* *} P=0.0003 ;{ }^{* *} P<0.0001 P_{(A-a) .} \mathrm{O}_{2}$ Alveolar-arterial oxygen gradient; $\mathrm{PaO}_{2}$ Partial pressure of oxygen in arterial blood; $\mathrm{SO}_{2}$ Oxygen saturation detected by pulse oximetry

to sepsis complicated by hepatorenal syndrome, the other from gastrointestinal bleeding. Another patient died after six months of follow-up, following sepsis-associated encephalopathy. One more patient was lost due to spontaneous bacterial peritonitis and hepatorenal syndrome after eight months of follow-up. Of the three patients who completed 12 months of follow-up, one died at home (the cause of which could not be ascertained), another died following an episode of variceal bleeding and the third patient died after 15 months of follow-up, following sepsis associated with nonhealing pressure sores. The mortality was higher among patients in group $2(\mathrm{P}=0.052$ [log rank test]), as illustrated by the Kaplan-Meier plot (Figure 2), and approached statistical significance.

\section{DISCUSSION}

A pathological dilation of intrapulmonary vessels, characteristically precapillary arteriovenous communication mainly at the base of the lungs, has been observed in patients with HPS (27-29) and can explain not only the abnormalities seen with CEE and perfusion lung scan, but also the reversibility 
of hypoxemia on oxygen therapy in some patients with HPS. The significantly longer duration of disease in patients with evidence of IVPD (HPS and IS, Table 1), may suggest a persistence of pathology (imbalance between vasoconstrictors and vasodilators) over long periods of time in patients with portal hypertension that bring about the structural changes in the base of the lung.

Abrams and Fallon (22) showed that $40 \%$ of patients had an increase of at least $10 \mathrm{mmHg}$ in their arterial oxygen pressure after treatment with garlic. Garlic supplementation in the present study was associated with a $24.66 \%$ increase in arterial oxygen pressure and a $28.35 \%$ decrease in alveolar-arterial oxygen gradient among patients with HPS. In the present study, arterial oxygen pressure was significantly higher after nine months among patients receiving garlic than in those receiving placebo $(\mathrm{P}<0.001$; Table 2$)$. Also, alveolar-arterial oxygen gradient was significantly lower after nine months among those receiving garlic compared with placebo $(\mathrm{P}<0.001$; Table 2). Fourteen of 21 patients $(66.67 \%)$ responded to oral garlic supplementation (group 1) after nine months of follow-up (intent-to-treat analysis). A responder was defined as reversal of evidence of intrapulmonary vascular shunts indicated by a negative $\mathrm{CEE}$, with normalization of alveolar arterial oxygen gradient. In group 1,10 patients $(47.62 \%)$ became HPS negative after three months of oral garlic supplementation therapy. An additional two patients showed reversal after six months and as many as three patients after nine months of garlic therapy; thus, as many as five patients with HPS required prolonged garlic supplementation before they had reversal of HPS, suggesting that prolonged garlic therapy may be required in some patients to obtain the desired results. In the present study, the patients received garlic at doses of $1 \mathrm{~g} / \mathrm{m}^{2} /$ day to $2 \mathrm{~g} / \mathrm{m}^{2} /$ day for the duration of study. Further studies are needed to reach a consensus regarding the dose and duration of garlic supplementation for individuals with HPS. Garlic was found to be safe in the present study, and its supplementation in the form of capsules containing garlic oil was not associated with any complications except for occasional breath odour.

It is noteworthy that, even among patients in group 2 (placebo), there was an improvement in arterial oxygen saturation and a reduction in alveolar-arterial oxygen gradient, with one patient showing reversal of HPS after six months. The spontaneous resolution of HPS, although unusual, has been reported previously (30). This particular patient was suffering from chronic liver disease due to hepatitis B, with hepatits B e antigen positivity, a high initial viral load (greater than 105 copies/mL), and a baseline liver biopsy showing activity with areas of fibrosis and nodule formation. Subsequently, after inclusion in the study, the patient received and responded to antiviral therapy including adefovir with lamivudine, with normalization of liver enzymes and a reduction of viral load to less than 100 copies $/ \mathrm{mL}$ after six months of therapy. Several vasodilators have been implicated in the genesis of pulmonary and systemic vasodilation in patients with HPS. The origin of these vasodilators has been a topic of controversy, with some (31) implicating the liver as a source of these agents, either due to increased local production or impaired hepatic clearance. This control of the primary disease may have a role in the improvement of hepatic function and a reduction of these circulating vasodilators, thus promoting the resolution of HPS in this patient. This may also

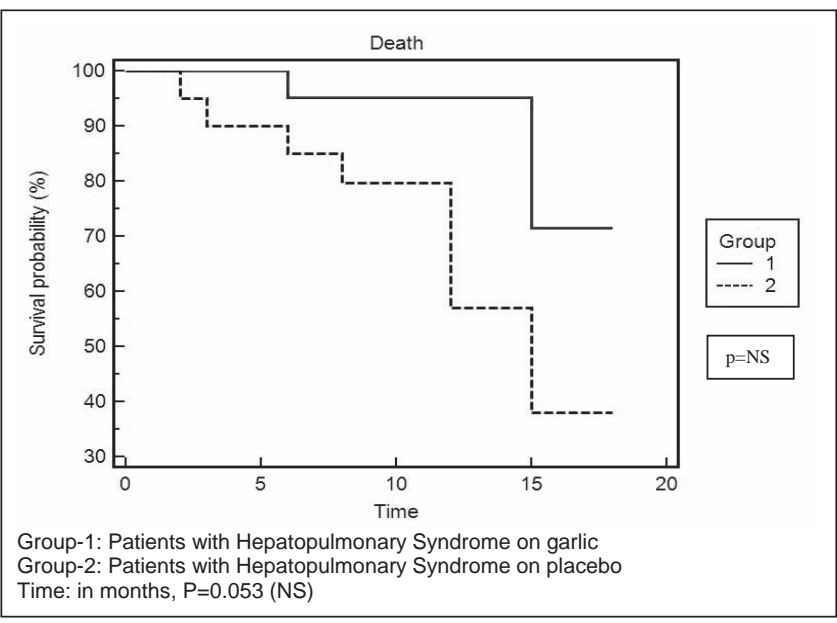

Figure 2) Kaplan-Meier survival curve of patients with hepatopulmonary syndrome on garlic (group 1) or placebo (group 2). NS Not statistically significant

explain the mild improvement in oxygen saturation and reduction in the alveolar-arterial gradient for the partial pressure of oxygen in other patients receiving placebo (group 2, Table 2).

The exact mechanism of how garlic aids in the resolution of HPS is not known. It was hypothesized (32) that garlic inhibits $\mathrm{NO}$ synthesis in macrophages, resulting in a reduced concentration in the hypoxic tissue. Ku et al (33) reported that active garlic metabolites are capable of inducing pulmonary vasodilation in rats. Garlic is believed to cause an increase in the rate of $\mathrm{NO}$ synthesis (34-36); thus, garlic should have been expected to worsen HPS. Abrams and Fallon (22) speculated that garlic use results in uniform vasodilation throughout the lung, resulting in a redistribution of pulmonary blood flow to apical and mid lung fields, improving the $\mathrm{V} / \mathrm{Q}$ ratios in these regions. This occurs because in HPS, the vessels are maximally dilated at the base of the lungs (as evidenced by a lack of the normal fall in pulmonary vascular resistance following exercise) and, hence, cannot be further dilated or recruited during exercise (37); therefore, they are nonresponsive to the increased $\mathrm{NO}$ production evoked by garlic. However, the uniform vasodilation throughout the lung accounts for the improvement in V/Q observed in patients with HPS. This improvement in V/Q caused by garlic may subsequently reduce $\mathrm{NO}$ synthesis in the lung bases (13), causing a reduction in the IVPD at the base of the lung and, subsequently, CEE negativity on prolonged garlic supplementation.

The incidence of nonfatal and fatal events was much lower among patients receiving garlic than in those receiving placebo (Table 2). The mortality was higher among patients receiving placebo $(\mathrm{P}=0.052$ [log-rank test]), and approached statistical significance (as illustrated by the Kaplan-Meier plot, Figure 2). It would be difficult to confirm how much of this improvement is due to garlic supplementation. It must be reiterated that these patients continued to receive medications for their primary disease (such as antiviral therapy, steroids in case of autoimmune liver disease and pharmacotherapy for portal hypertension), which may have had some role in the overall improvement of patient well-being.

Due to technical limitations, it was not possible for us to measure NO levels and evaluate the effects of garlic supplementation on NO levels in patients with HPS. 


\section{CONCLUSION}

Results of the present study suggest that garlic has some beneficial effects and may have a role in the reversal of HPS - the mechanism of which remains uncertain. Because it is a harmless substance, and has been a constituent of the daily diet for centuries, garlic holds the potential for further study. Assessment of the hemodynamic changes and measurement of NO levels is needed before this herb can be used routinely for therapy in patients with HPS.

\section{REFERENCES}

1. Lange PA, Stoller JK. The Hepatopulmonary syndrome. Ann Int Med 1995;122:521-9.

2. Rodriguez-Rolsin R, Agusti AG, Roca J. The Hepatopulmonary syndrome: New name, old complexities. Thorax 1992;47:897-902.

3. Agusti AGN, Roca J, Bosch J, et al. The lung in patients with cirrhosis. J Hepatol 1990;10:251.

4. Berthelot P, Walker JG, Sherlock S, et al. Arterial changes in the lungs in cirrhosis of the liver. Lungs spider nevi. N Engl J Med 1996;274:291.

5. Krowka MJ, Cortese DA. Hepatopulmonary syndrome. Current concepts in diagnostic and therapeutic considerations. Chest 1994;105:1528-37.

6. Agusti AG, Roca J, Rodriguez-Roisin R, et al. Pulmonary hemodynamics and gas exchange during exercise in liver cirrhosis. Am Rev Respir Dis 1989;139:485-91.

7. Andrivet P, Cadranel J, Housset B, et al. Mechanisms of impaired arterial oxygenation in patients with liver cirrhosis and severe respiratory insufficiency - effects of indomethacin. Chest 1993;103:500-7.

8. Andrivet P, Cadranel J, Housset B, Herigault R, Harf A, Adnot S. Mechanisms of impaired arterial oxygenation in patients with liver cirrhosis and severe respiratory insufficiency. Effects of indomethacin. Chest 1993;103:500-7.

9. Shijo H, Sasaki H, Yuh K, Sakaguchi S, Okumura M. Effects of indomethacin on hepatogenic pulmonary dysplasia. Chest 1991;99:1027-9.

10. Krowka MJ, Cortese DA. Severe hypoxemia associated with liver disease: Mayo Clinic experience and the experimental use of almitrine bismesylate. Mayo Clin Proc 1987;62:164-73.

11. Krowka MJ, Dickson ER, Cortese DA. Hepatopulmonary syndrome. Clinical observations and lack of therapeutic response to somatostatin analogue. Chest 1993;104:515-21.

12. Chen NS, Barnett CA, Farrer PA. Reversibility of intrapulmonary arteriovenous shunts in liver cirrhosis documented by serial radionucleotide perfusion lung scans. Clin Nucl Med 1984;9:270-82.

13. Shijo H, Sasaki H, Sakata H, Kusuhara H, Ueki T, Okumura M. Reversibility of hepatopulmonary syndrome evidenced by serial pulmonary perfusion scan. Gastroenterol Jpn 1993;28:126-31.

14. McCloskey JJ, Schleien C, Schwarz K, Klein A, Colombani P. Severe hypoxemia and intrapulmonary shunting resulting from cirrhosis reversed by liver transplantation in a pediatric patient. J Pediatr 1991;118:902-4.

15. Dimand RJ, Heyman MB, Bass NM, Lake JR, Roberts JP, Ascher NL. Hepatopulmonary syndrome: Response to hepatic transplantation. Hepatology 1991;14:55A. (Abst)

16. Rodriguez-Roisin R, Krowka M. Is severe arterial hypoxemia due to hepatic disease an indication for liver transplantation? A new therapeutic approach. Eur Respir J 1994;7:839-42.
17. De BK, Sen S, Biswas PK, et al. Occurrence of hepatopulmonary syndrome in Budd-Chiari syndrome and the role of venous decompression. Gastroenterology 2002;122:897-903.

18. Saad NE, Lee DE, Waldman DL, Saad WE. Pulmonary arterial coil embolization for the management of persistent type I hepatopulmonary syndrome after liver transplantation. J Vasc Interv Radiol 2007;18:1576-80.

19. Castro M, Krowka MJ. Hepatopulmonary syndrome. A pulmonary vascular complication of liver disease. Clin Chest Med 1996;17:35-48.

20. Krowka MJ, Cortese DA. Hepatopulmonary syndrome. Current concepts in diagnostic and therapeutic considerations. Chest 1994:105:1528-37.

21. Caldwell SH, Jeffers LJ, Narula OS, Lang EA, Reddy KR, Schiff ER. Ancient remedies revisited: Does Allium sativum (garlic) palliate the hepatopulmonary syndrome? J Clin Gastroenterol 1992;15:248-50.

22. Abrams GA, Fallon MB. Treatment of hepatopulmonary syndrome with Allium sativum L (garlic): A pilot trial. J Clin Gastroenterol 1998;27:232-5.

23. MN Sani, HR Kianifar, A Kianee, G Khatami. Effect of oral garlic on arterial oxygen pressure in children with hepatopulmonary syndrome. World J Gastroenterol 2006;21:2427-31.

24. Gomez FP, Martinez-Palli G, Barbera JA, Roca J, Navasa M, Rodriguez-Roisin R. Gas exchange mechanism of orthodeoxia in hepatopulmonary syndrome. Hepatology 2004;40:660-6.

25. Fallon MB, Abrams GA. Cardiovascular and pulmonary complications in patients with liver disease. In: Zakim D, Boyer TD, eds. Hepatology: A Textbook of Liver Diseases. Vol 1. Saunders, Elsevier Sciences, 2003:529.

26. Seshiah V, Sundaram A, Hariharan RS, Ramanakumar TK, Moses SGP. Garlic oil (Garlic Pearls Ranbaxy) in hyperlipidemia secondary to diabetes mellitus. Research Society for Study of Diabetes in India. $1983<$ http://www.rssdi.org/1983_dec/original_ paper5.pdf> (Version current at May 20, 2009).

27. Agusti AGN, Roca J, Bosch J, et al. The lung in patients with cirrhosis. J Hepatol 1990;10:251.

28. Berthelot P, Walker JG, Sherlock S, et al. Arterial changes in the lungs in cirrhosis of the liver. Lungs spider nevi. N Engl J Med 1966;274:291-8.

29. Krowka MJ, Cortese DA. Hepatopulmonary syndrome. Current concepts in diagnostic and therapeutic considerations. Chest 1994;105:1528-37.

30. Saunders KB, Fernando SS, Dalton HR, Joseph A. Spontaneous improvement in a patient with the hepatopulmonary syndrome assessed by serial exercise tests. Thorax 1994;49:725-7.

31. Huffmyer JL, Nemergut EC. Respiratory dysfunction and pulmonary disease in cirrhosis and other hepatic disorders. Respir Care 2007;52:1030-6.

32. Nagae S, Ushijima M, Hatono S, et al. Pharmacokinetics of the garlic compound S-allylcysteine. Planta Med 1994;60:214-7.

33. Ku DD, Abdel-Razek TT, Dai J, Kim-Park S, Fallon MB, Abrams GA. Garlic and its active metabolite allicin produce endothelium- and nitric oxide-dependent relaxation in rat pulmonary arteries. Clin Exp Pharmacol Physiol 2002;29:84-91.

34. Stoller JK, Moodie D, Schiavone WA, et al. Reduction of intrapulmonary shunt and resolution of digital clubbing associated with primary biliary cirrhosis after liver transplantation. Hepatology 1990;11:54-8.

35. Egen-Schwind C, Eckard R, Kemper FH. Metabolism of garlic constituents in the isolated perfused rat liver. Planta Med 1992;58:301-5.

36. Ip C, Lisk DJ. Bioavailability of selenium from selenium-enriched garlic. Nutr Cancer 1993;20:129-37.

37. Wagner PD, Gale GE, Moon RE, et al. Pulmonary gas exchange in humans exercising at sea level and simulated altitude. J Appl Physiol 1986;61:260. 


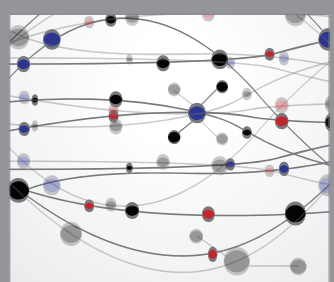

The Scientific World Journal
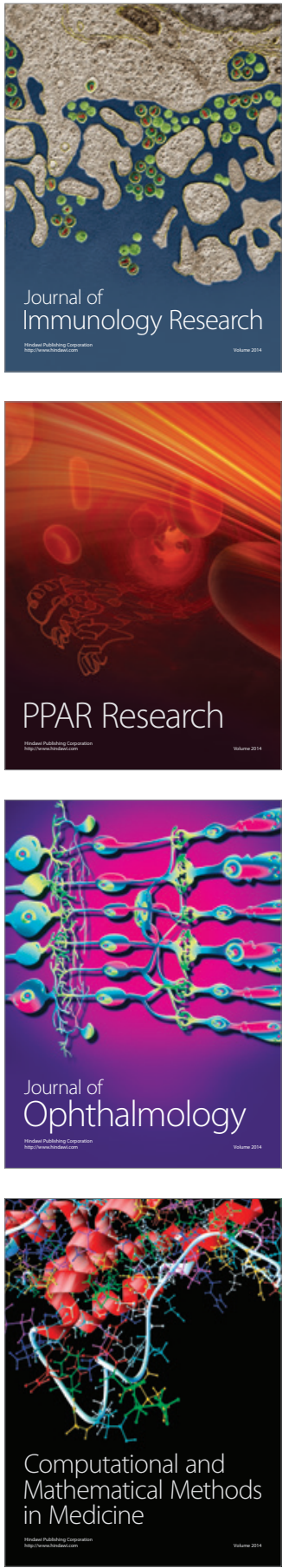

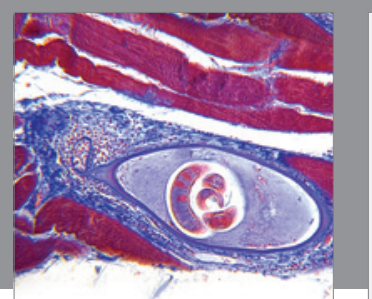

Gastroenterology Research and Practice

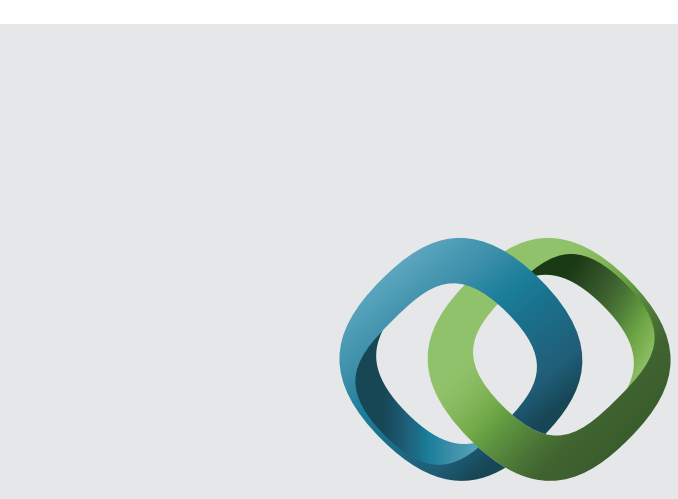

\section{Hindawi}

Submit your manuscripts at

http://www.hindawi.com
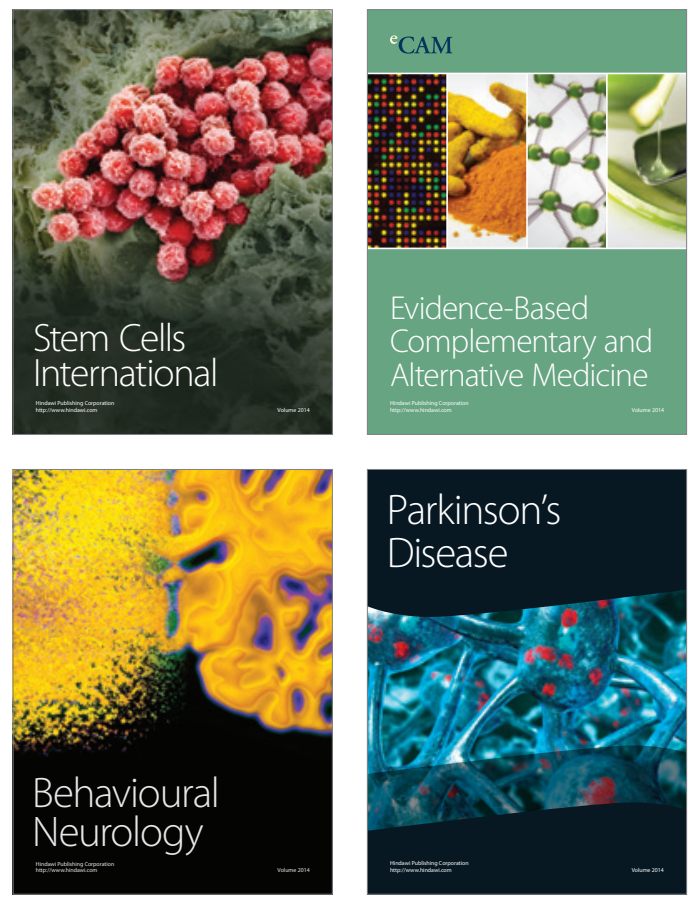
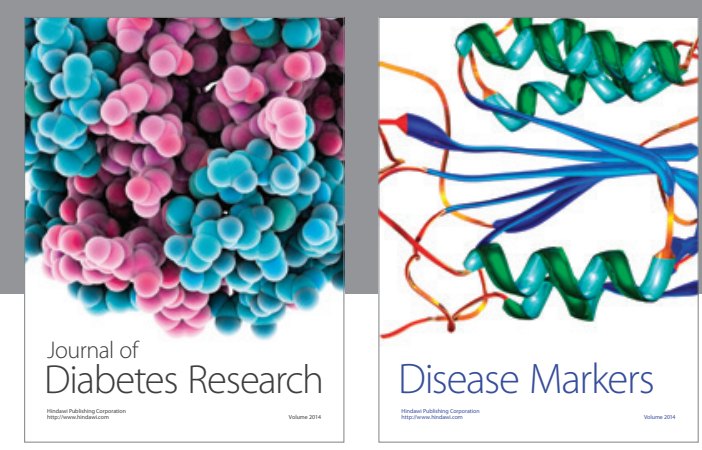

Disease Markers
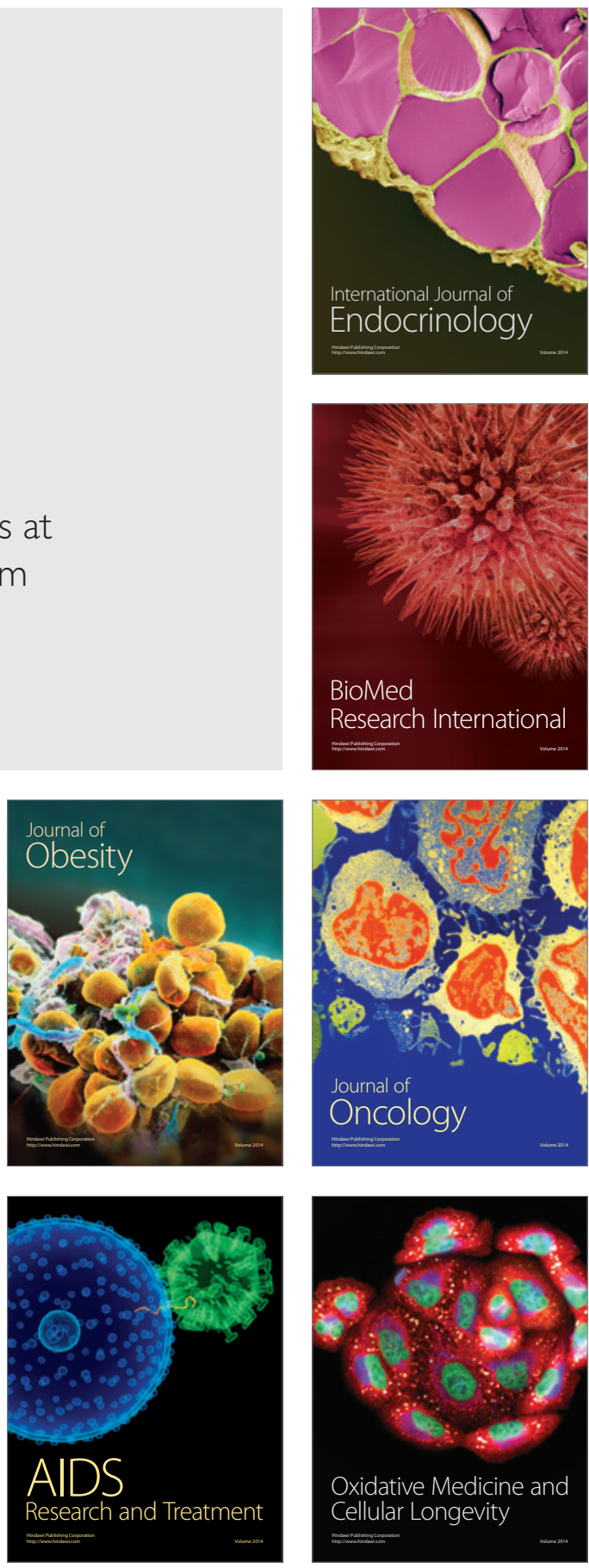